Thorax (1968), 23, 683.

\title{
Maximal acid output and oesophagitis in hiatus hernia $^{1}$
}

\author{
B. H. SQUIRE, S. GLICK, AND ANN BENN \\ From the United Birmingham Hospitals
}

\begin{abstract}
It has been suggested (Casten, Bernhang, Nach, and Spinzia, 1963) that patients with symptomatic sliding hiatus hernia have a higher acid output than the normal patient, but this has recently been disputed by Williams, Lawrie, and Forrest (1967). These latter workers found that there is no significant increase in maximal acid output in patients with sliding hiatus hernia. Aylwin (1953) demonstrated a correlation between the degree of oesophagitis in sliding hiatus hernia and the enzyme activity of juices bathing the oesophagus at night, and suggested that this was the chief factor in the production of oesophagitis. In this study patients with hiatus hernia were investigated to see if there was any correlation between the degree of oesophagitis and the maximal acid output. The maximal acid output in patients with hiatus hernia was found not to differ significantly from normal, and the degree of oesophagitis in the patients with oesophageal reflux was not closely related to the maximal acid output.
\end{abstract}

\section{MATERIAL}

Fifty-seven patients admitted for surgical repair of symptomatic hiatus hernia were studied. All patients had pre-operative barium studies to detect gastrooesophageal reflux, oesophageal stricture, and gastric or duodenal ulceration. Oesophagoscopy was also carried out in every case to determine the presence and degree of oesophagitis.

Of the 57 patients, 21 were men and 36 were women, with an age range from 33 to 77 years. Fifty patients had sliding hiatus herniae; seven of these had strictures and one had a Schatzki's ring. Six patients had paraoesophageal herniae and one patient had oesophageal reflux without demonstrable hiatus hernia.

In the series seven patients were known to have had duodenal ulceration, six of whom had sliding hiatus herniae and one of whom had a paraoesophageal hernia. In all patients a thoraco-abdominal approach was used for repair of the hiatus hernia, and no evidence of duodenal ulceration was found in any other patient on direct examination of the duodenum.

\section{TECHNIQUE}

MAXIMAL ACID OUTPUT This was determined by histamine tests on all patients-in 15 by the augmented histamine test (Kay, 1953), and in 42 by the histamine infusion test (Lawrie, Smith, and Forrest, 1964).

In all patients a Salem sump double-lumen tube was passed into the stomach and the patient was

1Reprints may be obtained from Mr. J. Leigh Collis, at the Queen Elizabeth Hospital, Edgbaston, Birmingham 15 positioned until a satisfactory aspiration of gastric juice was obtained. In those patients with a stricture, this was first dilated, and the following day the tube was passed into the stomach, under radiographic control if any difficulty was encountered. After emptying the stomach, the histamine test was carried out according to Kay (1953) or Lawrie et al. (1964). In every case the aspiration was personally supervised by one of us, and the tube was cleared and repositioned as necessary. All specimens of gastric juice were titrated to a $\mathrm{pH}$ of $\mathbf{7 \cdot 4}$ and the result was expressed in milliequivalents of total acid per hour. In order to give comparable results between the augmented histamine test and the histamine infusion test the 15-45 min. output of the augmented histamine test was doubled and compared to the one-hour value of the histamine infusion test.

Ten patients have been excluded from this series because of inadequate collections or failure to complete the test, usually because of vomiting, or because it was not possible to pass the Salem tube beyond the stricture.

\section{OESOPHAGOSCOPY}

It is appreciated that the naked-eye differentiation of degrees of oesophagitis is of limited accuracy, especially in distinguishing between grades of intermediate severity, and that it is only reliable over large series ; nevertheless, it is a generally accepted method of expressing degrees of oesophagitis (Aylwin, 1953). Biopsy was not routinely carried out as the patients were usually submitted to definitive surgery within the next few days and we consider that the histological appearance of oesophagitis in small fragments of 
tissue taken from one part of the circumference of the oesophagus may bear little relationship to the general overall picture of oesophagitis even at the same level.

Oesophagoscopy was carried out in all cases under general anaesthesia, and the degree of oesophagitis present was graded as follows: $O$, no oesophagitis ; A, mild oesophagitis - a reddening of the mucosa ; B, moderate oesophagitis-a red mucosa which bled readily as a result of mild trauma but not spontaneously ; C, severe oesophagitis-frank ulceration often with spontaneous bleeding taking place or stricture formation.

\section{RESULTS}

The distribution of maximal acid output in this group is shown in Fig. 1 plotted against age for both men and women. The mean maximal acid output for the patients with sliding hiatus herniae without duodenal ulceration (45 cases) was $21 \cdot 1$ $\mathrm{mEq} / \mathrm{hr}$. The mean for the six patients with duodenal ulceration as well as sliding hiatus hernia was $39 \cdot 1 \mathrm{mEq} / \mathrm{hr}$.

The degree of oesophagitis was recorded in 50 of the 51 patients with gastro-oesophageal reflux.
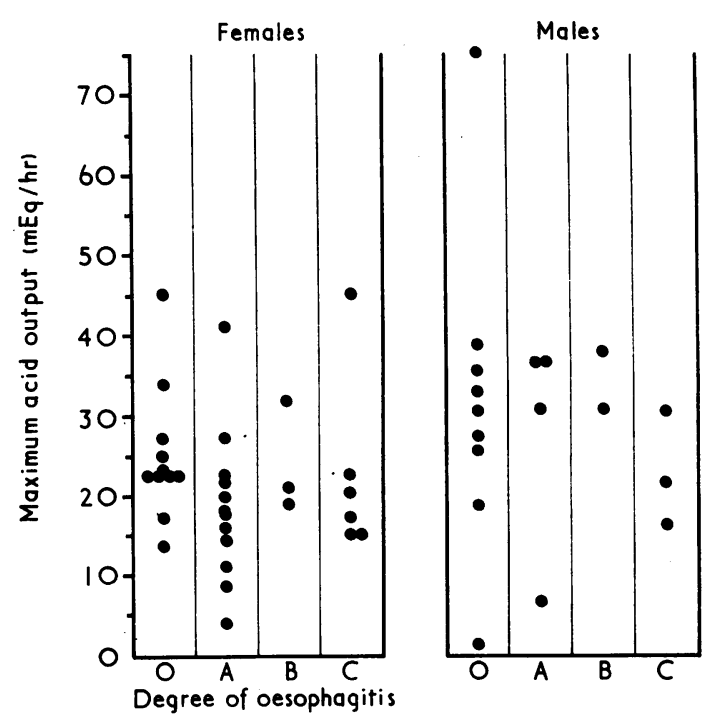

FIG. 2. M.A.O. varies widely for all degrees of oesophagitis and increasing severity of oesophagitis does not appear to be related to an increase in the M.A.O.

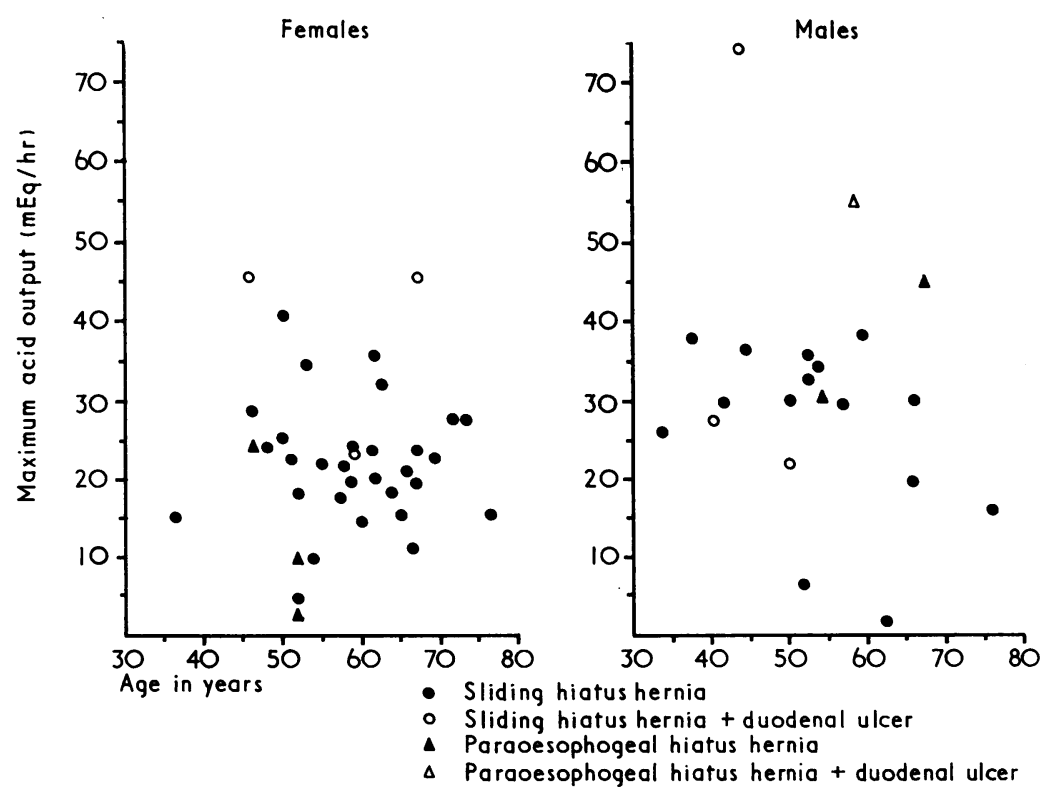

FIG. 1. A wide range of M.A.O. found at all ages in patients with hiatus hernia. Mean M.A.O. for patients with sliding hiatus hernia without duodenal ulceration 21.1 $\mathrm{mEq} \mathrm{HCl} / \mathrm{hr}$ and for those with duodenal ulceration $39 \cdot 1 \mathrm{mEq} \mathrm{HCl} / \mathrm{hr}$. 
Twenty patients had grade $O$ oesophagitis, 16 grade $\mathbf{A}$, five grade $\mathbf{B}$, and nine grade $\mathbf{C}$ (Fig. 2).

The mean maximal acid output for patients with grade $\mathrm{O}$ was $28.2 \mathrm{mEq} / \mathrm{hr}$, for grade A 20.9 $\mathrm{mEq} / \mathrm{hr}$, for grade B $28.0 \mathrm{mEq} / \mathrm{hr}$, and for grade C $22.4 \mathrm{mEq} / \mathrm{hr}$.

\section{DISCUSSION}

It has been suggested that patients with sliding hiatus hernia produce more acid than normal patients (Casten et al., 1963 ; Winkelstein, Wolf, Som, and Marshak, 1954). In this series no evidence was found to support this claim, as the mean maximal acid output in hiatus hernia without duodenal ulcer was within the normal range (Williams et al., 1967).

It was thought that the degree of oesophagitis in patients with oesophageal reflux could be related to the amount of acid produced under maximal stimulation with histamine, but no support for this assumption was found, as shown by the wide variation of the mean maximal acid output in the four grades of oesophagitis. It may be that the type of reflux is more important, as has been suggested by Piccone, Gutelius, and McCorriston
(1965). Using oesophageal motility with $p \mathrm{H}$ studies they found that there were long and short reflux patterns, and severe symptoms were associated with patients having long duration patterns of reflux. Possibly the degree of oesophagitis is related to the length of time the acid remains in the oesophagus after reflux, and to the degree of reflux that occurs, especially at night.

We wish to thank Mr. J. Leigh Collis for his interest and encouragement and for allowing us to use findings from patients admitted under his care.

\section{REFERENCES}

Aylwin, J. A. (1953). The physiological basis of reflux oesophagitis in sliding hiatal diaphragmatic hernia. Thorax, 8, 38.

Casten, D. F., Bernhang, A., Nach, R. J., and Spinzia, J. (1963). A physiological basis for the surgical treatment of sliding esophageal hiatal hernia. Surg. Gynec. Obstet., 117, 87.

Kay, A. W. (1953). Effect of large doses of histamine on gastric secretion of $\mathrm{HCl}$. Brit. med. J., 2, 77.

Lawrie, J. H., Smith, G. M. R., and Forrest, A. P. M. (1964). The histamine-infusion test. Lancet, 2, 270.

Piccone, V. A., Gutelius, J. R., and McCorriston, J. R. (1965). A multiphased esophageal $\mathrm{pH}$ test for gastroesophageal reflux. Surgery, 57, 638.

Williams, C. B., Lawrie, J. H., and Forrest, A. P. M. (1967). Acid secretion in symptomatic sliding hiatus hernia. Lancet, 1, 184.

Winkelstein, A., Wolf, B. S., Som, M. L., and Marshak, R. H. (1954). Peptic esophagitis with duodenal or gastric ulcer. J. Amer. med. Ass., 154, 885 . 